\title{
The Effects of Bile Acid Feeding on the Development of Ileal Bile Acid Transport
}

\author{
BENJAMIN L. SHNEIDER, GREGORY A. MICHAUD, A. BRIAN WEST, AND \\ FREDERICK J. SUCHY \\ Department of Pediatrics, Division of Pediatric Gastroenterology/Hepatology [B.L.S., G.A.M., and F.J.S.], and \\ the Department of Pathology [A.B.W.], Yale University, New Haven, Connecticut 06510
}

\begin{abstract}
Sodium-dependent bile acid uptake is developmentally regulated in the rat ileum. Transport activity is abruptly expressed on postnatal $d$ 17, although the mechanisms controlling this expression are poorly understood. Changes in bile salt metabolism and hepatic transport result in a marked increase in bile flow before postnatal $\mathrm{d} 17$, and thus this study examined the effects of bile salt feeding on the development of ileal bile acid transport. Twelve-d-old rat pups were gavage-fed saline, taurocholate, or mannitol on a daily basis for $3 \mathrm{~d}$. Sodium-dependent bile acid transport was studied by rapid filtration using ileal brush-border membrane vesicles prepared from the various experimental groups. Taurocholate feeding resulted in precocious development of sodium-dependent bile acid transport and induction of sucrase activity. Mannitol feeding, used as a control for the effects of diarrhea-induced stress, resulted in similar sucrase activity, yet sodium-dependent bile acid transport was induced to only half the level observed in taurocholate-fed animals $(3.2 \pm 1.6$ versus 6.9 $\pm 2.0 \mathrm{pmol} / \mathrm{mg}$ protein $/ 45 \mathrm{~s}, p<0.001)$. Serum corticosterone levels were similar in the mannitol- and taurocholate-fed animals $(3.8 \pm 1.3$ versus $4.6 \pm 1.8 \mu \mathrm{g} / \mathrm{dL})$. Both feedings lead to histologic maturation of the ileum, with a more pronounced effect in the taurocholate-fed pups. Bile salt feeding induces precocious expression of ileal bile acid transport, apparently by both diarrhea-induced stress and a bile salt-specific effect. (Pediatr Res 33: 221-224, 1993)
\end{abstract}

\section{Abbreviations}

BBMV, brush-border membrane vesicles

A variety of factors have been implicated in controlling the wide range of structural and biochemical alterations that occur during the development of the neonatal rat intestine. The normal rise in endogenous corticosteroid and thyroid hormone levels just before many of these changes is suggestive of their role in the regulation of this process $(1,2)$. Further evidence of their role is seen in the effects of pharmacologic doses of these hormones and/or adrenalectomy (3-5). Dietary changes at weaning result in major alterations in luminal substrates, which induce digestive enzyme expression $(5,6)$. Finally, s.c. implantation studies suggest that intestinal ontogeny may be "hard-wired" ( 7 , 8).

Sodium-dependent bile acid uptake in the rat ileum is abruptly expressed on d 17 of postnatal life, although the mechanisms

Received June 22, 1992; accepted October 22, 1992.

Correspondence and reprint requests: Benjamin L. Shneider M.D., Yale University Department of Pediatrics, 333 Cedar St., Box 3333, New Haven, CT 06510

Supported in part by Grants HD 07388 and DK 43509 from the National Institutes of Health. controlling this change in expression are not well understood (911). It has been demonstrated that pharmacologic doses of corticosteroids will induce precocious development of this transporter, whereas the effects of intestinal lumen contents on this system remain unstudied $(11,12)$. Before d 17 of postnatal life, significant changes in bile salt metabolism occur, including expansion of the bile salt pool and the development of hepatic transport mechanisms; the end result is an increase in bile flow (13-16). The following studies were undertaken to assess the effects of bile salts on the development of the ileal bile acid transport system.

\section{MATERIALS AND METHODS}

Animals and reagents. Natural litters of 12-d-old SpragueDawley rat pups were obtained from Charles River (Raleigh, NC). Diagnostic glucose and leucine aminopeptidase kits were obtained from Sigma Chemical Co. (St. Louis, MO). Twentygauge stainless steel, curved, ball-tipped gavage feeding tubes were obtained from Popper and Sons, Inc. (New Hyde Park, NY). ${ }^{3} \mathrm{H}$-taurocholic acid was obtained from the Dupont Co. (Boston, MA). All other reagents were of the highest grade available.

Animal feeding. Animals were housed, fed, and handled according to the NIH Guide for the Care and Use of Laboratory Animals and under a protocol approved by the Yale Animal Care and Use Committee. Experiments were performed on single natural litters of 12-d-old rat pups that were housed with the natural mother and exposed to 12-h day/night cycles. At the start of the experiment, the pups were randomized to two or three groups, identified by ear punch, and weighed. The pups were gavage-fed a volume of $2 \mathrm{~mL} / 100 \mathrm{~g}$ body weight daily (between 1600 and $1800 \mathrm{~h}$ ) on three consecutive days (i.e. postnatal d 12 to 14). The formulations of the feedings were: saline, $245 \mathrm{mM} \mathrm{NaCl}$; taurocholate, $95 \mathrm{mM}$ sodium taurocholate + $150 \mathrm{mM} \mathrm{NaCl}$; and mannitol, $570 \mathrm{mM}$ mannitol. Dosedependence studies were performed with alterations in volume of identical concentration formulations. Animals were weighed on postnatal d 15.

Membrane preparation/characterization. Animals were killed by decapitation, and a $20-\mathrm{cm}$ segment of terminal ileum and a $15-\mathrm{cm}$ segment of proximal jejunum were obtained. Tissues were homogenized and BBMV were prepared as previously described (10). Sucrase levels were measured in ileal and jejunal homogenates. Brush-border membrane protein enrichment was assayed using leucine aminopeptidase as a marker (12). Intravesicular volumes were estimated by measuring the uptake of $\mathrm{L}-\left[{ }^{3} \mathrm{H}\right]$ alanine into BBMV at equilibrium $(60 \mathrm{~min})$ in the presence of a $100-\mathrm{mM}$ sodium or potassium thiocyanate gradient (10). Protein levels were measured by the method of Lowry et al. (17). Serum corticosterone levels were measured by RIA (Endocrine Sciences, Calabasas Hills, CA). Distal ileal tissue was fixed in Carnoy's 
solution and embedded in paraffin. Sections cut at $5 \mu \mathrm{m}$ were stained with hematoxylin and eosin.

Transport. Membrane vesicle transport was assayed in quadruplicate using the rapid filtration method (10). Briefly, 40 to 70 $\mu \mathrm{g}$ of protein in BBMV were suspended in a solution of $2.2 \mu \mathrm{M}$ ${ }^{3} \mathrm{H}$-taurocholate, $50 \mathrm{mM}$ mannitol, and $100 \mathrm{mM} \mathrm{NaCl}$ or $\mathrm{KCl}$. After a $45-\mathrm{s}$ incubation (time of maximal uptake) at $37^{\circ} \mathrm{C}$, transport was stopped by the addition of ice-cold $50 \mathrm{mM}$ mannitol, $100 \mathrm{mM} \mathrm{NaCl}$, or $\mathrm{KCl}$. BBMV were then isolated using a $0.45-\mu \mathrm{m}$ nitrocellulose Millipore filter, and associated radioactivity was assayed by liquid scintillation. Sodium-dependent transport was defined as the difference in vesicle-associated radioactivity in the presence of a $100-\mathrm{mM}$ sodium versus a $100-\mathrm{mM}$ potassium gradient.

Statistical analysis. All values are reported as the mean $\pm \mathrm{SD}$. Means were compared using $t$ test.

\section{RESULTS}

Taurocholate versus saline feeding. Pups in four separate litters were randomized in four separate experiments to receive taurocholate or saline feedings. The feedings were well tolerated by both groups, with no significant difference in final weight (taurocholate $29.1 \pm 3.1$, saline $29.3 \pm 3.6 \mathrm{~g}$ ). Modest diarrhea was observed in the taurocholate-fed pups but not the saline-fed animals. Brush-border membrane protein yield was similar in the two groups, and both preparations demonstrated 8- to 12fold enrichment in leucine aminopeptidase. BBMV-associated taurocholate in the presence of a $\mathrm{K}^{+}$gradient was similar in the two groups (saline 14.6 \pm 3.7 ; taurocholate $12.2 \pm 3.2 \mathrm{pmol} / \mathrm{mg}$ protein $/ 45 \mathrm{~s} ; n=12$ in each group), thus demonstrating no significant differences in binding or passive diffusion of bile salts. $\mathrm{Na}^{+}$-dependent uptake of taurocholate was present in taurocholate-fed animals but not in the saline controls (Fig.1). The observed taurocholate uptake was approximately $20 \%$ of that measured in BBMV from adult rats in our laboratory $(32.2 \pm$ $8.1 \mathrm{pmol} / \mathrm{mg}$ protein $/ 45 \mathrm{~s}, n=$ nine assays from five BBMV preparations). Sucrase activity was 2 - to 3 -fold elevated in homogenates from taurocholate-fed pups compared with saline-fed controls. Histologic examination of the saline-fed animals revealed a developmentally appropriate apical endocytic complex in enterocytes lining the entire surface of the villi, whereas the

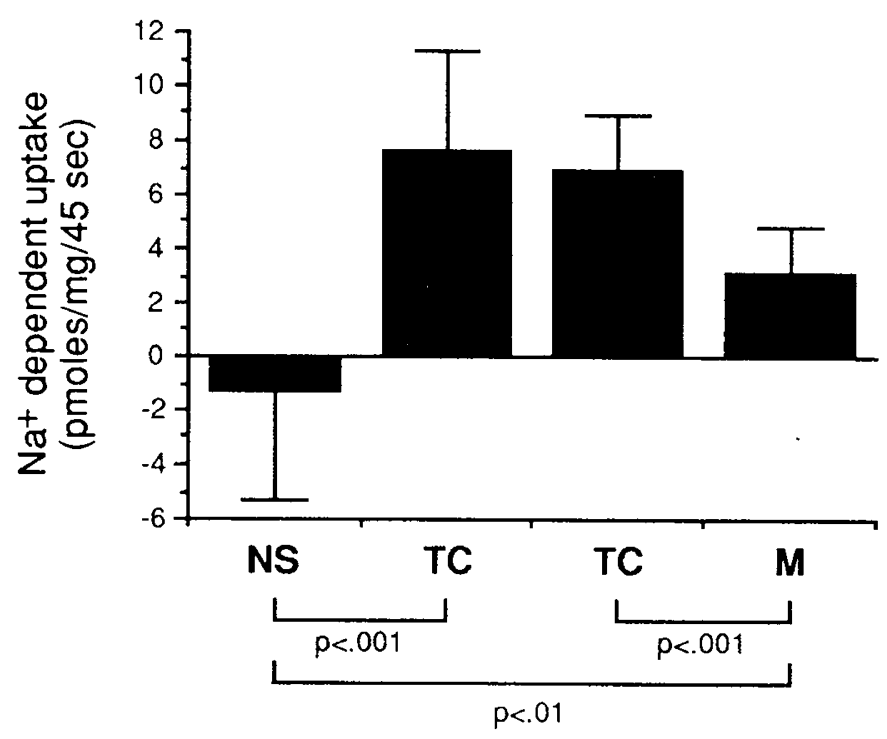

Feeding

Fig. 1. Taurocholate transport. The results of taurocholate $(T C)$ vs saline $(N S)(n=16$ measurements in each) and taurocholate vs mannitol $(M)(n=12$ measurements in each) feeding on sodium-dependent bile acid transport are depicted. taurocholate-fed animals had a more mature phenotype without an endocytic complex except at the tip, where a small number of less mature forms remained (18; Fig. 2).

Dose-dependency studies. Because of concerns that the above effects might be secondary to diarrhea-induced stress, limited studies of the dose-dependency of this response were undertaken (19). In one set of experiments, a litter was randomly divided into three groups, and the pups were fed 10, 25, and $95 \mathrm{mM}$ taurocholate. Sodium-dependent bile acid transport was not seen in the pups fed 10 and $25 \mathrm{mM}$ taurocholate. Sucrase activity was elevated only in the pups fed $95 \mathrm{mM}$ taurocholate. In an effort to determine a control feeding that would result in similar diarrhea and sucrase induction, a variety of mannitol doses were tested. A litter of rat pups was randomized to receive 95,265 , or $530 \mathrm{mM}$ mannitol. A modest diarrhea was seen in the pups that received the highest dose of mannitol, yet no significant sodiumdependent bile acid transport was observed. Sucrase activity was induced to a level that approached that seen in the taurocholatefed animals, and thus a slightly higher concentration was chosen as the osmotically active control feeding.

Taurocholate versus mannitol feeding. Pups in three separate litters were randomized in three separate experiments to receive either $95 \mathrm{mM}$ sodium taurocholate $+150 \mathrm{mM}$ sodium chloride or $570 \mathrm{mM}$ mannitol. Both feedings were well tolerated by the rat pups (Table 1). Weight gain and survival were not significantly different. Enrichment of leucine aminopeptidase in the BBMV versus ileal homegenate was approximately 10 -fold in both groups. Intravesicular volumes of the BBMV prepared from both the mannitol- and taurocholate-fed animals were similar to those of normal 15-d-old pups (normal $1.33 \pm 0.14$, mannitol $1.31 \pm$ 0.28 , taurocholate $1.42 \pm 0.07 \mu \mathrm{L} / \mathrm{mg}$ protein, $n=6$ for each). In addition, modest diarrhea was seen in both sets of animals, and homogenate sucrase activities were similar. Serum corticosterone levels in a limited number of mannitol, taurocholate, and normal pups were also not significantly different (normal $3.45 \pm$ 1.23 , mannitol $3.78 \pm 1.26$, taurocholate $4.64 \pm 1.78 \mu \mathrm{g} / \mathrm{dL}, n$ $=5$ for each). Ileal histology revealed partial maturation in the mannitol-fed animals (Fig. 2). Sodium-dependent bile-acid transport was seen in vesicles from both groups with 2-fold higher transport in the taurocholate-fed pups (Fig. 1). BBMV-associated taurocholate in the presence of a $\mathrm{K}^{+}$gradient was similar in the two groups (mannitol $9.6 \pm 2.7$, taurocholate $10.6 \pm 1.6 \mathrm{pmol} /$ $\mathrm{mg}$ protein $/ 45 \mathrm{~s} ; n=12$ in each group), again demonstrating no significant differences in binding or passive diffusion of bile salts.

\section{DISCUSSION}

This study clearly demonstrates that gavage feeding of taurocholic acid will induce precocious development of sodiumdependent bile acid transport in the rat ileum. The feedings were well tolerated by the animals and had no effect on the preparation of BBMV. The dose of bile acids that was associated with the induction of transport activity is in the range of the daily output of bile salts by a 21-d-old rat pup (16). Smaller doses did not appear to induce any effect. The critical issue is the specificity of these effects on the precocious development of bile acid transport activity.

Two separate control feedings and three measures of intestinal maturation were used in this study to clarify the specificity of the effects of bile-salt feeding. In the initial experiments, an isoosmotic feeding of saline was used. This was meant to control for the physical stress of daily gavage feedings and for the effects of the administration of a volume of hyperosmotic liquid. The taurocholate feedings led to a precocious induction of bile acid transport with evidence of more global maturation, including increased sucrase activity and absence of the apical endocytic complexes. There was no evidence of maturation in the salinefed animals. Although the saline feedings served as an adequate control for the stresses of orogastric gavage feeding of hypertonic solution, they did not appear to induce diarrhea. Thus, it appears 


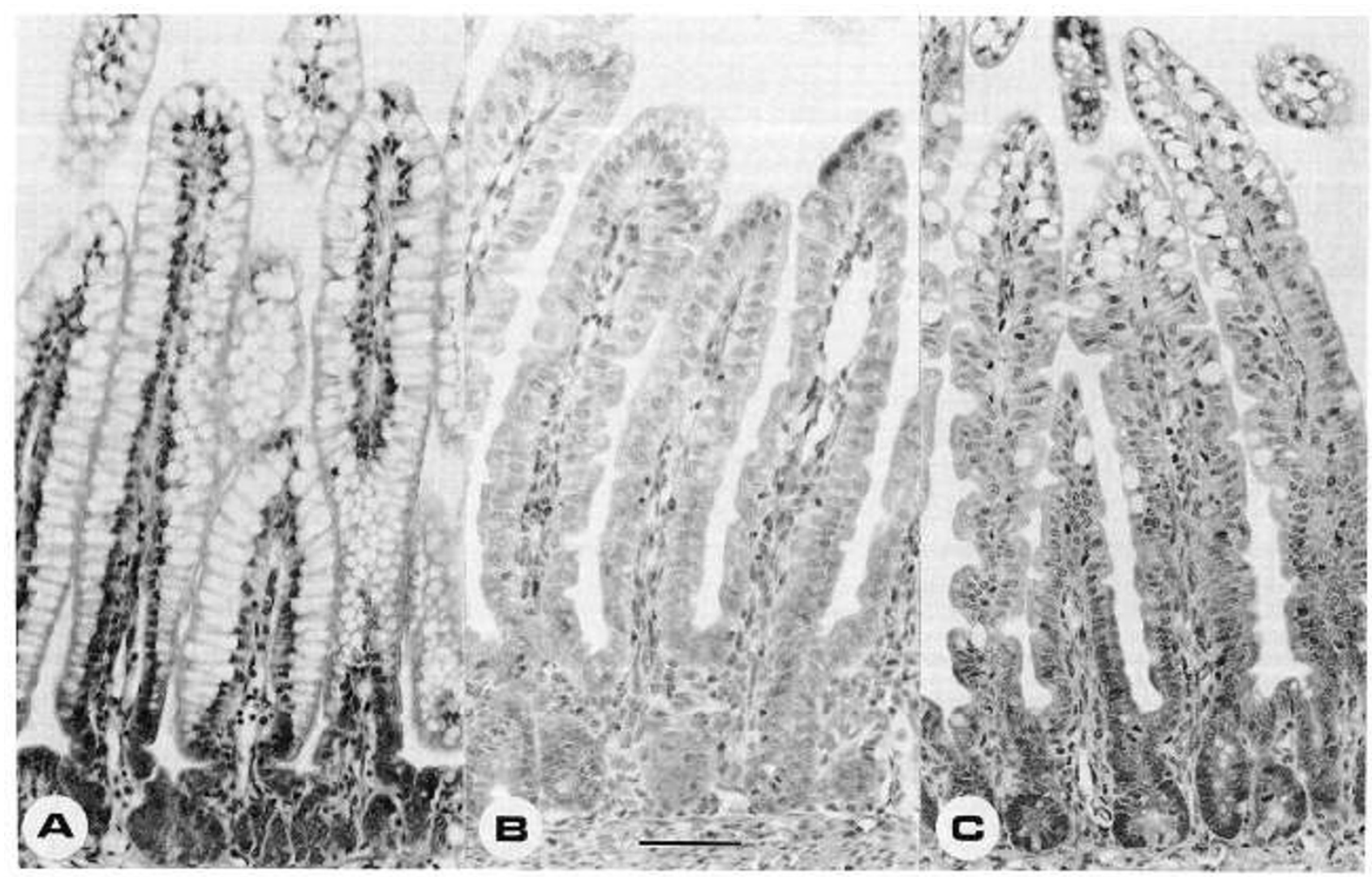

Fig. 2. Histologic features of ileal mucosa in 15 -d-old rat pups after gavage-feeding with saline $(A)$, taurocholate $(B)$, or mannitol $(C)$ for $3 \mathrm{~d}$. No morphologic effects of feeding saline were observed when compared with normal 15-d-old controls (not illustrated). Taurocholate gavage-feeding led to a marked reduction in the number of villus epithelial cells containing apical endocytic complexes that, instead of lining the entire villus, became confined to the villus tips. They were replaced by adult-type enterocytes that populated about $90 \%$ of the villus surface. The effects of mannitol were qualitatively similar, but quantitatively less marked. Hematoxylin and eosin stain; bar, $50 \mu \mathrm{m}$.

Table 1. Taurocholate and mannitol feeding results*

\begin{tabular}{lcc}
\hline & Taurocholate & Mannitol \\
\hline No. of animals & 19 & 19 \\
\% Survivors & 89 & 89 \\
Initial wt $(\mathrm{g})$ & $23.6 \pm 3.5$ & $24.4 \pm 3.7$ \\
Final wt $(\mathrm{g})$ & $28.4 \pm 5.2$ & $29.9 \pm 4.3$ \\
$\quad$ Homogenate sucrase & & \\
$\quad(\mu \mathrm{mol} / \mathrm{h} / \mathrm{mg}$ protein $)$ & $0.28 \pm 0.08$ & $0.38 \pm 0.15$ \\
$\quad$ Ileum & $0.56 \pm 0.30$ & $0.39 \pm 0.12$ \\
$\quad$ Jejunum & $11.4 \pm 1.8$ & $10.2 \pm 2.3$ \\
\hline LAP enrichment &
\end{tabular}

$* p>0.05$ for all comparisons. LAP, leucine aminopeptidase.

that these saline feedings were not an adequate control for the cathartic effects of bile salt feedings.

Bile salts can induce diarrhea by both osmotic and colonspecific secretory effects (20). Mannitol was used as a control for the osmotic effects, although the effects of gavage administration of osmotically active material can be difficult to interpret. Sucrose feedings induce precocious development of sucrase activity in the developing rat intestine (5). Adrenalectomized rat pups who were fed sucrose did not display precocious development of sucrase activity (5), although these were not healthy animals, as indicated by their poor weight gain and the high mortality of this procedure (21). Adrenalectomized animals who were supplemented with pharmacologic doses of cortisone underwent precocious development of sucrase activity. This induction was increased 5-fold by the simultaneous administration of gavage feedings of sucrose (5). In a separate series of experiments, mannitol feeding, which led to modest diarrhea and elevation of serum corticosterone levels, also induced precocious development of sucrase activity (19). Thus, the interpretation of the effects of gavage feeding of an osmotically active compound needs to account for diarrhea-induced stress.

The dose of mannitol that was used as a control was based on our preliminary dose-dependence studies. Compared with the amount of bile salts administered, at least six times the amount of nonabsorbable osmotically active compound in the form of mannitol was required to induce diarrhea and a similar increase in sucrase activity. This may be evidence of a more specific effect of bile salts or may reflect bile salt-activated secretory diarrhea. The exact timing of the expression of this developmentally regulated secretory diarrhea is unknown, but these studies indicate that it may exist at a time when intestinal bile salt reclamation processes are immature $(9,10,20)$.

Further evidence of a specific response to bile salts is suggested by the degree of induction of bile acid transport relative to other markers of intestinal maturation. $\mathrm{Na}^{+}$-dependent bile acid transport was induced to a significantly greater level in the taurocholate-fed versus mannitol-fed pups. Sucrase activity, as a marker of diarrhea-induced stress, was similar in both groups. In addition, corticosterone levels, a more direct measure of stress, were also not significantly different. Taurocholate feeding led to a nearly complete disappearance of the apical endocytic complexes, whereas mannitol induced only a partial change. The dissociation of this phenotypic response from the other markers of maturity has been induced with the administration of epidermal growth factor to suckling rats (22). It is not clear if this is evidence of an alternative pathway for inducing these precocious changes.

In summary, the results of gavage-feeding 12-d-old rat pups with saline, mannitol, or taurocholate suggest that ileal bile acid transport can be precociously induced by both diarrheal stress and a bile salt-specific effect. Changes in bile salt metabolism and hepatic transport lead to marked increases in bile flow, 
which may be a stimulus for ileal development. Interestingly, the response to bile salt feedings at this age is clearly different from the down-regulation of bile acid transport that has been reported in adult rats (23). The receptors that mediate these effects and their mechanisms of action are unknown. Direct studies of bile acid-induced effects on development will be facilitated by the purification of the ileal bile acid transporter and by the cloning of its gene and promoter elements.

Acknowledgments. The authors thank Dr. Otakar Koldovsky of the Department of Pediatrics at The University of Arizona for his helpful comments and criticisms.

\section{REFERENCES}

1. Walker P, Dubois JD, Dussault JH 1980 Free thyroid hormone concentrations during postnatal development in the rat. Pediatr Res 14:247-249

2. Henning SJ 1978 Plasma concentrations of total and free corticosterone during development in the rat. Am J Physiol 235:E451-E456

3. Yeh KY, Yeh M, Holt PR 1991 Intestinal lactase expression and epithelial cell transit in hormone-treated suckling rats. Am J Physiol 260:G379-G384

4. Yeh KY, Yeh M, Holt PR 1989 Differential effects of thyroxine and cortisone on jejunal sucrase expression in suckling rats. Am. J Physiol 256:G604-G612

5. Lebenthal E, Sunshine P, Kretchmer N 1972 Effect of carbohydrate and corticosteroid on activity of alpha-glucosidases in intestine of the infant rat. $\mathrm{J}$ Clin Invest 51:1244-1250

6. Raul F, Simon PM, Kedinger M, Grenier JF, Haaffen K 1978 Sucrase and lactase synthesis in suckling rat intestine in response to substrate administration. Biol Neonate 33:100-105

7. Yeh KY, Holt PR 1986 Ontogenic timing mechanism initiates the expression of rat intestinal sucrase activity. Gastroenterology 90:520-526

8. Diamond JM 1986 Hard-wiring local triggering of intestinal enzyme expression. Nature 324:408

9. Barnard JA, Ghishan FK, Wilson FA 1985 Ontogenesis of taurocholate transport by rat ileal brush border membrane vesicles. J Clin Invest 75:869-873

10. Moyer MS, Heubi JE, Goodrich AL, Balistreri WF, Suchy FJ 1986 Ontogeny of bile acid transport in brush border membrane vesicles from rat ileum. Gastroenterology 90:1188-1196

11. Little JM, Lester R 1980 Ontogenesis of intestinal bile salt absorption in the neonatal rat. Am J Physiol239:G319-G323

12. Barnard JA, Ghishan FK 1986 Methylprednisolone accelerates the ontogeny of sodium-taurocholate cotransport in rat ileal brush border membranes. $J$ Lab Clin Med 108:545-555

13. Suchy FJ, Bucuvalas JC, Novak DA 1987 Determinant of bile formation during development: ontogeny of hepatic bile acid metabolism and transport Semin Liver Dis 7:77-84

14. Anathanrayanan M, Bucuvalas JC, Shneider BL, Sippel CJ, Suchy FJ 1991 An ontogenically regulated $48-\mathrm{kDa}$ protein is a component of the $\mathrm{Na}+$-bile acid cotransporter of rat liver. Am J Physiol 261:G810 G817

15. Novak DA, Sippel CJ, Ananthanarayanan M, Suchy FJ 1991 Postnatal expression of the canalicular bile acid transport system of rat liver. Am J Physiol 260:G743-G751

16. Piccoli DA, Maller ES, Vanderslice RR, Watkins JB 1986 Bile salt secretion in the developing rat: implications for cholestasis. Gastroenterology 90:A 1801(abstr)

17. Lowry DH, Rosebrough NJ, Farr AL, Randall RJ 1951 Protein measurement with the Folin phenol reagent. J Biol Chem 193:265-275

18. Wilson JM, Whitney JA, Neutra MR 1991 Biogenesis of the apical endosomelysosome complex during differentiation of absorptive epithelial cells in rat ileum. J Cell Sci 100:133-143

19. Goda T, Yamada K, Bustamante S, Edmond J, Grimes J, Koldovsky O 1985 Precocious increase of sucrase activity by carbohydrates in the small intestine of suckling rats. I. Significance of the stress of sugar-induced diarrhea. J Pediatr Gastroenter Nutr 4:468-475

20. Potter GD, Sellin JH, Burlingame SM 1991 Bile acid stimulation of cyclic AMP and ion transport in developing rabbit colon. J Pediatr Gastroenterol Nutr 13:335-341

21. Henning SJ 1981 Postnatal development: coordination of feeding, digestion, and metabolism. Am J Physiol 241:G199-G214

22. Harada E, Hashimoto Y, Syuto B 1990 Epidermal growth factor accelerates the intestinal cessation of macromolecular transmission in the suckling rat. Comp Biochem Physiol 97A:201-204

23. Lillinenau J, Munoz J, Longmire-Cook SJ, Crombie DL, Hofmann AF 1991 Negative feedback regulation of the ileal bile acid transport system: the second site of regulation of the enterohepatc circulation. In: Paumgartner $G$, Stiehl A, Gerok W (eds) Bile Acids as Therapeutic Agents. Kluwer Academic Publishers, Boston, pp 163-165 